\title{
Nest-boxes for Common Swifts Apus apus as compensatory measures in the context of building renovation: efficacy and predictors of occupancy
}

\author{
TONIO SCHAUB, PETER J. MEFFERT and GERALD KERTH
}

\section{Summary}

Currently, renovation and thermal insulation of buildings is happening at a high rate in many European countries, driven in part by the political aim to reduce greenhouse gas emissions. Unfortunately, building renovations often lead to a loss of structures, such as accessible cavities, on which synanthropic species, for example house-nesting birds, depend. In Germany, due to legislative regulations, it is a common practice to install nest-boxes as compensation for destroyed nest sites of birds. However, studies on the efficacy of such measures remain sparse. We monitored the occupancy of 477 compensatory nest-boxes for Common Swifts Apus apus, predominantly placed on renovated prefabricated buildings in a city in Germany. We found $24.3 \%$ of the boxes occupied by Swifts. On most buildings, the number of occupied boxes was as high as or even higher than the assumed number of breeding sites prior to renovation. Furthermore, in a district where nearly all buildings had been renovated in the past 10 years, we recorded a remarkably high density of Swifts breeding in nest-boxes. Using boosted regression trees, we analysed whether eight different nest-box properties influenced box occupation probability. The number of neighbouring boxes was the most important. Additionally, box age, facade orientation, city district, relative and absolute height, and manner of installation (external/internal) also played a role. Between different nest-box types, we found only negligible differences in occupation probability. Our findings suggest that installing nest-boxes is likely to be an appropriate measure to compensate for nesting sites of Swifts lost during building renovations. Based on our results, we recommend mounting the boxes a few metres apart from each other and close to the roof edge to maximise success. Further studies should be carried out to assess whether our results and conclusions can be confirmed in other situations.

\section{Introduction}

Increasing urbanisation, and the resulting habitat loss, is a major driver of the current biodiversity crisis (Czech et al. 2000, Mcdonald et al. 2008, Laurance 2010). However, human settlements also provide suitable habitat for animals. For example, many synanthropic bird and mammal species find shelters and breeding sites in or on buildings. Whether these can serve as an important resource for animals depends on certain characteristics of the buildings, such as the availability of accessible cavities. In the course of building renovations and demolitions, such structures often vanish. This phenomenon is readily observable in Europe, where modernisation and thermal insulation of buildings is currently happening at a high rate in order to improve energy efficiency (BMWi 2011, EU 2012). This development has the potential to lead to a strong decline of building-dependent species if it is not accompanied by appropriate mitigation measures.

In Germany, all naturally occurring bird species are protected under the Federal Nature Conservation Act, which implies a general prohibition on destroying their breeding sites, even outside the breeding season (Deutscher Bundestag 2009). If it is impossible to maintain such sites during building renovations or demolitions, the responsible authorities usually mandate compensatory measures. Similar regulations exist in Poland, for example (Luniak and Grzeniewski 2011). 
However, studies on the efficacy of compensatory measures such as the installation of nestboxes remain sparse. Here, we present a study on the occupancy of nest-boxes for the Common Swift Apus apus (hereafter Swift). The boxes had been mounted to mitigate the loss of nesting sites during the renovation or demolition of buildings in Greifswald, north-eastern Germany. As in many other cities of the former Eastern Bloc, a large number of prefabricated buildings have been renovated in Greifswald during the last 20 years, resulting in a substantial loss of cavities suitable as breeding sites for Swifts.

Swifts are aerial insectivores that inhabit a large Palearctic breeding range, covering the Mediterranean, temperate, and boreal zones (Cramp 1985). The wintering grounds are mainly located in central and southern Africa (Cramp 1985, Åkesson et al. 2012). In most parts of the range, nesting sites in buildings nowadays outnumber the original nesting sites in rock crevices and tree cavities (Cramp 1985), which is partly due to the rarity of the latter structures in managed forests (Günther et al. 2004). In buildings, Swifts find suitable cavities under the eaves, in gaps in walls, under roof tiles (Weitnauer and Scherner 1980), and in the horizontal interstices between the concrete slabs of prefabricated buildings (Lehmann 2005).

Changes in the construction of buildings are considered to be a major threat for Swifts (Gory 1997, Bauer et al. 2005, Crowe et al. 2010), and it is known that renovations can cause considerable local declines in Swift populations (Braun 1999). However, data on population trends at a larger scale are ambiguous. In Germany, Südbeck et al. (2007) judged the Swift population to be stable and not threatened, whereas Sudfeldt et al. (2012) estimated a decline of $1-3 \%$ per year between 1991 and 2010. Population declines were reported from other European countries (BirdLife International 2004, Eaton et al. 2009, Crowe et al. 2010), but the overall European population was considered to be stable between 1980 and 2010 (PECBMS 2012).

Nest-boxes are widely used in many European countries to support Swift populations, e.g. in Germany (Kaiser 1993, Wortha and Arndt 2004, Arens 2011), Poland (Luniak and Grzeniewski 2011), Switzerland (Weitnauer 1980) and the UK (Lack and Lack 1951, Wilson 2011). Recommendations on how to install nest-boxes for Swifts can be found in various brochures for building owners and architects. These agree that Swifts require an unobstructed flight path in front of the boxes (Kaiser 1993, Du Feu 2003, Scholl 2004). Moreover, nest-boxes should have a certain minimum size and should be placed at a minimum height above ground level $(5-7 \mathrm{~m})$, with little exposure to direct sunlight (Kaiser 1993, Scholl 2004, Mayer 2013). As Swifts are gregarious (Cramp 1985), it is generally recommended to install several boxes close to each other (Kaiser 1993, Du Feu 2003). It is also possible to attract Swifts to new potential breeding sites by playing Swift calls. This can considerably shorten the time Swifts need to detect the new sites, especially when existing colonies are relatively far away (Arens 2004, Tigges and Mayer 2011). Furthermore, because of the Swift's pronounced nest-site fidelity (Cramp 1985), it is suggested to carry out renovation work outside the breeding season and either to preserve the original cavities or to install compensatory nest-boxes in exactly the same places (Scholl 2004).

Anecdotal reports of nest-boxes occupied by Swifts are not rare (e.g. Lack and Lack 1951, Weitnauer 1980, Kaiser 1993, Arens 2011), but to the best of our knowledge, there is only one published and detailed empirical study on how frequently nest-boxes are used by Swifts. Wortha and Arndt (2004) monitored c.1,200 compensatory nest-boxes for Swifts in Berlin, Germany, and found the overall proportion of occupied boxes to be only about $10 \%$. Moreover, at 15 out of 16 buildings, fewer Swifts were breeding in the boxes than in the original cavities before the renovation work. However, this study lacked both a clearly defined survey method and a multi-factorial statistical analysis showing the influence of nest-box properties on box occupancy.

Against the background of indications of a population decline in Swifts, ongoing renovations of buildings in many countries, and uncertainty regarding the efficacy of mitigation practices, we aimed to answer the following questions, using detailed field observations and multi-factorial statistics: 1) what proportion of compensatory nest-boxes are occupied by Swifts? 2) How do the numbers of occupied boxes relate to the numbers of breeding sites before the renovations? 3) Which properties of the boxes influence the occupation probability? 


\section{Methods}

\section{Study site}

Our study was conducted in Greifswald, Mecklenburg-Western Pomerania, Germany $\left(54^{\circ} \mathrm{O} 5^{\prime} \mathrm{N}\right.$, $13^{\circ} 24^{\prime} \mathrm{E}$ ), a city with approximately 56,000 inhabitants (Statistisches Amt MecklenburgVorpommern 2013). In spring 2013, there were nearly 800 nest-boxes for Swifts on facades of buildings throughout the city. Out of those, we selected 477 boxes installed on 23 buildings. Boxes were selected in order to ensure a sufficient sample size for several different box properties (see below). Twenty-two of the studied houses were prefabricated apartment buildings. The number of storeys ranged between two and six. All boxes had been mounted between 2004 and 2012. No attraction calls were used on any of the sites. Most of the buildings had been renovated and equipped with a thermal insulation shell (Figure 1 ), but at three buildings, the boxes had been installed as compensation for the demolition of another building nearby. Contrary to the general advice, all buildings except one had been renovated during the Swift breeding season. The time of year when renovation is performed is supposed to have a large effect on occupation probability: if it takes place during the Swifts' stay in Africa, the birds which used to breed on the building will probably return afterwards and readily occupy the compensatory boxes. If renovation is carried out during the breeding season, the Swifts that find their former breeding sites inaccessible will look out for nest sites elsewhere and will normally not return the year after renovation (Scholl 2004). Consequently, the building needs to be rediscovered as a breeding site by different individuals. To ensure comparability, the four nest-boxes at the single building that had been renovated outside the breeding season were excluded from the analysis concerning the box properties.

It was possible to obtain data on the number of Swift breeding sites prior to renovation for 1o buildings or sections of buildings. These data were taken from expert assessments that had been conducted to determine the required amount of compensatory measures. When counts were available from two different years prior to renovation, we calculated the arithmetic mean. On all those buildings, more nest-boxes were installed than breeding sites had been detected prior to renovation (on average 6.7:1; Table I). Details on the survey method were not available in the expert assessments.

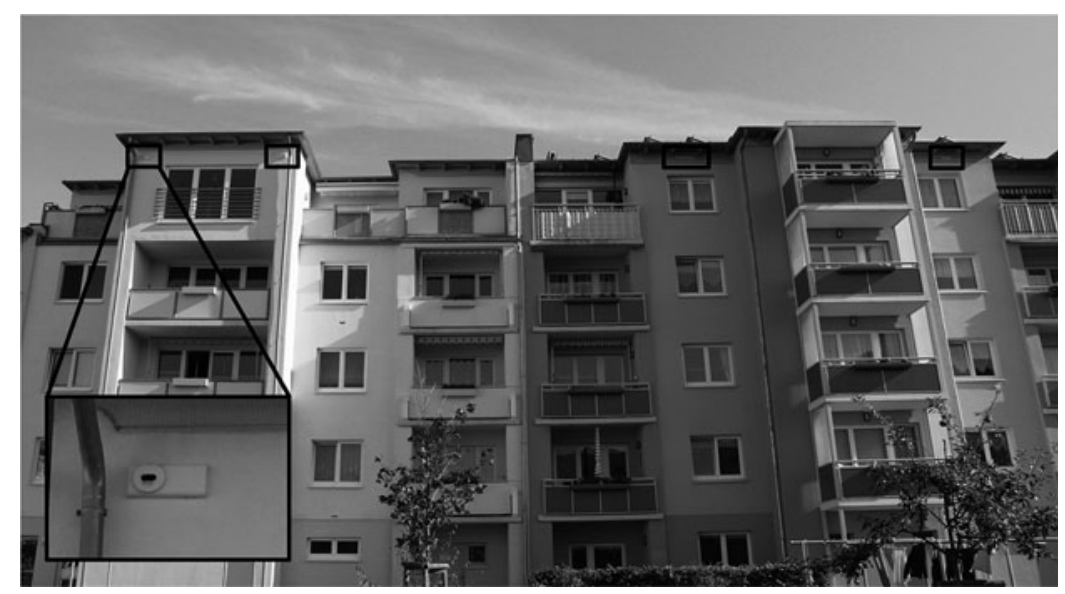

Figure 1. A section of a renovated prefabricated apartment-complex in Greifswald with five compensatory nest-boxes for Common Swifts (box type Schwegler 17). The boxes are integrated in the thermal insulation. Photograph by T. Schaub. 
Table 1. Comparison of the number of Swift breeding sites prior to renovation and in 2013 for 10 buildings (or sections of buildings). The numbers of breeding sites prior to renovation were taken from expert assessments. For buildings for which counts from two different years prior to renovation were available, the mean and range of breeding sites are indicated. NB = nest-boxes. ${ }^{*}$ : Buildings where not all nest-boxes were surveyed.

\begin{tabular}{lclllr}
\hline & \# NB & $\begin{array}{l}\text { Box age } \\
\text { (breeding } \\
\text { periods) }\end{array}$ & Breeding sites & \\
\cline { 3 - 5 } & & \# prior to renovation & $\# 2013$ & Relative change (\%) \\
\hline a) & 4 & 1 & 2 & 2 & \pm 0.0 \\
b) & 10 & 1 & $2.5(2-3)$ & 7 & +180.0 \\
c) & 35 & 0 & $5 \cdot 5(5-6)$ & $\geq 7$ & $\geq+27 \cdot 3$ \\
d) & 33 & 4 & 4 & 5 & +25.0 \\
e) & 33 & 2 & 5 & 0 & -60.0 \\
f) & 28 & 2 & 3 & 3 & -100.0 \\
g) & 13 & 0 & 2 & $\geq 1$ & +50.0 \\
h) & 13 & 0 & 1 & 5 & $\geq \pm 0.0$ \\
i) & 18 & 1 & $2.5(2-3)$ & 2 & \pm 100.0 \\
j) & 10 & 1 & 2 & $\geq 34$ & $\geq+15.3$ \\
Sum & 197 & & $29.5(28-31)$ & & 0 \\
\hline
\end{tabular}

\section{Swift survey}

To determine the occupancy of the boxes, all were visited once between 25 June and 9 July 2013. Boxes that were not found to be occupied by Swifts or other bird species during this first survey were monitored for a second time between 10 and 24 July 2013. These two periods correspond to the nestling period (Lack and Lack 1951, Weitnauer and Scherner 1980), when Swifts visit their nests most frequently (Arens 2011). The observations were carried out from oghoo to 15 h3o (CEST) and from 20 hoo to 45 minutes after sunset to cover the times with the highest feeding frequency (Lack and Owen 1955, Arens 2011). We performed the observations only during good weather (air temperature $>12{ }^{\circ} \mathrm{C}$, average wind speed $\leq 30$ $\mathrm{km} / \mathrm{h}$, no heavy or persistent rain). Each box was observed for $1 \mathrm{~h}$ per observation, but when average wind speed was more than $20 \mathrm{~km} / \mathrm{h}$, the observations lasted $1.5 \mathrm{~h}$ to correct for a presumed lower feeding activity in these conditions. In most cases, it was possible to observe several boxes at the same time. The total observation time was $270.5 \mathrm{~h}$. We defined a box to be occupied if at least once a Swift was observed entering or leaving it or if an individual (nestling or adult) was visible at the entrance. The same criteria were used for passerine species occupying the boxes.

For Ostseeviertel Parkseite, a 20 ha large section of the district Ostseeviertel (see below), it was possible to calculate a minimum population density of Swifts. Nearly all buildings in this area had been renovated since 2004, and therefore it was very unlikely that breeding sites outside the nest-boxes existed. We surveyed about $75 \%$ of all boxes in that area.

\section{Box properties}

We included eight different box properties as predictor variables in our analysis: box type, number of neighbouring boxes, absolute height, height relative to the roof edge, manner of installation, orientation, box age, and city district. Our sample included seven box types produced by two manufacturing companies (Schwegler, Schorndorf, Baden-Württemberg, Germany and Strobel, Schmölln, Thuringia, Germany): Schwegler 17, 17A, 17B, 17C, 1MF and Strobel 416 and 430 (Figure 2). Because of their similarity, the different variants of the Schwegler 17 group were pooled for the statistical analysis. None of the Strobel 416 boxes had been installed in the way intended by the manufacturer. The designated bottom side with the entrance hole had been 


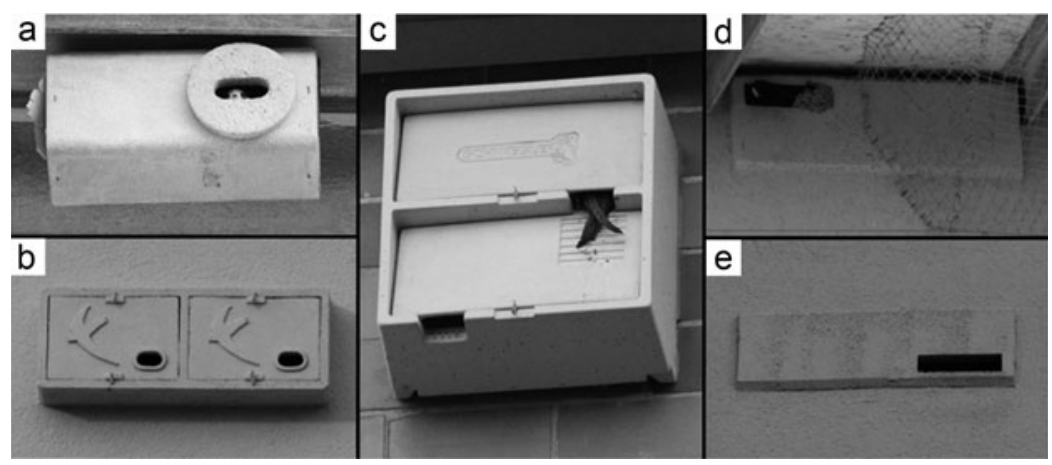

Figure 2. The different nest-box types studied. a: Schwegler 17 (single box); b: Strobel 430; c: Schwegler 1MF; d: Strobel 416t; e: Strobel 416b. Additionally, the Schwegler 17 box occurred in different variants: as double box $(17 C)$, triple box $(17 A)$ and as box with enlarged interior room $(17 B)$. Pictures a, $c$ and $d$ show Common Swifts at the box entrance holes. Note the loam traces on picture $\mathrm{d}$ indicating previous use by Northern House-martins. Photographs by T. Schaub.

turned to the front. We differentiated between Strobel 416 boxes with the entrance hole at the top $(416 \mathrm{t})$ and at the bottom $(416 \mathrm{~b})$ of the front side of the box (Figure $2 \mathrm{~d}, 2 \mathrm{e}$ ). For further information on the box types, see Table $S_{1}$ in the online Supplementary Materials.

Boxes were treated as a "group" if the distances between the entrances of adjacent boxes were less than $1 \mathrm{~m}$. We counted the number of boxes with which a given box was associated in a group ("number of neighbours"). The distances between the entrances were measured on photographs, where the known exterior dimensions of the boxes served as reference lengths. We grouped the boxes into the classes $0,1,2,3-5$, and 8-14 neighbouring boxes to ensure a sufficient sample size in each category.

The absolute height (height above ground level) and the distance to the roof edge ("relative height") were determined using a laser rangefinder (Bosch GLM 80). The absolute height ranged between 5.15 and $18.15 \mathrm{~m}$. Here, we chose the classes 5-7.9, 8-10.9, 11-13.9, and 14-19 $\mathrm{m}$, again to ensure sufficient sample sizes in the categories. The relative height was expressed in two categories, "at roof edge" and "not at roof edge", with a threshold distance to the roof edge of $2 \mathrm{~m}$.

Concerning the manner of installation, we distinguished between external and internal boxes, the latter being integrated in the thermal insulation. Box orientation was subdivided into four classes based on the cardinal orientation of the facade. We calculated the age of the boxes as the number of possible breeding periods (May to August) for Swifts from box installation up to (but not including) the 2013 breeding season. Finally, we considered the city district as a predictor variable with three categories: City centre, Ostseeviertel and Schönwalde. The former comprises a mixture of prefabricated and older houses and is characterised by a higher density of buildings than the two other districts, which almost exclusively consist of large prefabricated apartment complexes.

\section{Statistical analysis}

For the statistical analysis of the box properties' influence on occupation probability, we used boosted regression trees (BRT; Friedman 2001, Elith et al. 2008). This technique combines several advantages compared to parametric regression models: it can fit complex non-linear relationships, interaction effects between the predictor variables are automatically considered, and correlations between predictors, as well as missing data and outliers, do not pose numerical problems. Additionally, the resulting models show a higher predictive performance 
than conventional modelling methods, such as generalised linear models (Friedman and Meulman 2003, Elith et al. 2008). Instead of delivering p-values, BRT use internal validation processes, in our case 10 -fold cross-validation. The predictive performance of BRT models is described by the proportion of explained deviance, i.e. the variability explained by the model, and the crossvalidated AUC of the ROC (area under curve of the receiver operation characteristic) that quantifies, applied to our case, how well the model is able to discriminate between occupied and non-occupied nest-boxes. Three parameters can be adjusted within such models: I) tree complexity, defining the order of interactions considered in the model, 2) learning rate, controlling the contribution of each regression tree to the final model, and 3) bag fraction, determining the proportion of data which is held back at each step. Tree complexity was set to 5 , and subsequently, learning rate was adjusted to 0.001 so that at least 1,000 trees would be drawn (following Elith et al. 2008). We varied the bag fraction in order to maximise predictive performance; for the final analysis, a bag fraction of 0.7 was used. As box occupancy constitutes a binary response variable, a Bernoulli distribution was fixed in the model settings. We used the Software $R$ (version 3.o.I; $\mathrm{R}$ Core Team 2013), with the package $g b m$ (version 2.1; Ridgeway 2013). A spreadsheet with our raw data can be found in Table $\mathrm{S}_{2}$.

\section{Results}

\section{Nest-box occupancy}

In total, 116 boxes $(24.3 \%)$ were found to be occupied by Swifts, $102(21.4 \%)$ by House Sparrows Passer domesticus, and one each (o.2\%) by Black Redstarts Phoenicurus ochruros and Great Tits Parus major. We found loam traces at the entrances of 20 boxes $(4.2 \%)$, indicating previous use by Northern House-martins Delichon urbicum (Figure 2d). In Ostseeviertel Parkseite, we found 68 nest-boxes that were occupied by Swifts. Equating an occupied box with a breeding pair leads to a minimum density of 34 breeding pairs per 10 ha in that district.

For eight out of 10 buildings with data available for comparison, the number of occupied nest-boxes in 2013 was greater than, or equal to, the number of breeding sites that had been detected in the original cavities prior to renovation (Table 1 ). In two cases, the number of breeding sites had declined. In total, the number of breeding sites on those to buildings increased from 29.5 to at least 34 .

\section{Influence of box properties on the occupation probability}

The BRT model explained $27.3 \%$ of the total deviance with a cross-validated AUC of 0.765 (Table 2). The number of neighbouring boxes proved to have the highest relative influence on occupation probability (30.5\%). Boxes without neighbouring boxes within $1 \mathrm{~m}$ had the highest probability of being occupied by Swifts, and the occupation probability decreased with increasing

Table 2. Characteristics of the BRT model. $\mathrm{CV}=$ cross-validated; $\mathrm{AUC}=$ area under curve; $\mathrm{ROC}=$ receiver operation characteristic.

\begin{tabular}{lc}
\hline Characteristics of the BRT model & \\
\hline Number of trees & 3,100 \\
Mean total deviance & 1.104 \\
Proportion of explained deviance & $27.26 \%$ \\
Estimated CV deviance (standard error) & $0.951(0.025)$ \\
Training data correlation & 0.563 \\
CV correlation (standard error) & $0.387(0.036)$ \\
Training data AUC of the ROC & 0.854 \\
CV AUC of the ROC (standard error) & $0.765(0.018)$ \\
\hline
\end{tabular}



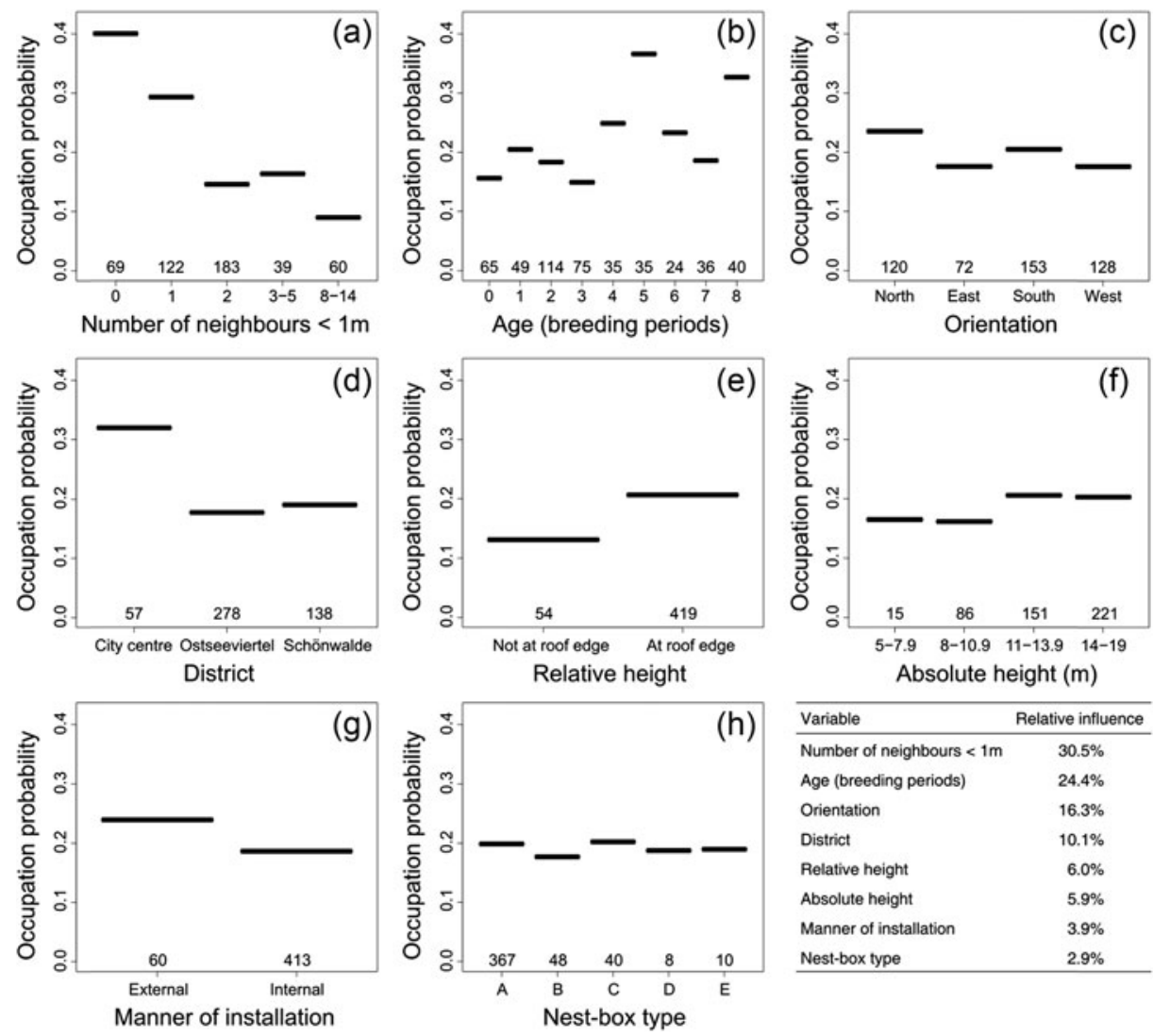

\begin{tabular}{lc}
\hline Variable & Relative influence \\
\hline Number of neighbours < $1 \mathrm{~m}$ & $30.5 \%$ \\
Age (breeding periods) & $24.4 \%$ \\
Orientation & $16.3 \%$ \\
District & $10.1 \%$ \\
Relative height & $6.0 \%$ \\
Absolute height & $5.9 \%$ \\
Manner of installation & $3.9 \%$ \\
Nest-box type & $2.9 \%$ \\
\hline
\end{tabular}

Figure 3. Modelled occupation probability of nest-boxes in relation to eight different box properties. Sample sizes for each category are given above the $\mathrm{x}$-axis. Number of neighbours was defined as the number of boxes with which a given box was associated in a group (distance between adjacent boxes $<1 \mathrm{~m}$ ). Box age was expressed as the number of possible breeding periods for Swifts before 2013. Boxes defined to be "at roof edge" were closer than $2 \mathrm{~m}$ to the roof edge. Nest-box types: $\mathrm{A}=$ Schwegler 17 group, $\mathrm{B}=$ Schwegler $1 \mathrm{MF}, \mathrm{C}=$ Strobel 416t, $\mathrm{D}=$ Strobel $416 \mathrm{~b}, \mathrm{E}=$ Strobel 430.

number of neighbours (Figure 3 a). None of the 60 boxes with at least eight neighbours was occupied (Table $3 \mathrm{f}$ ). The second most influential predictor variable was box age (24.4\%). Older boxes tended to have higher occupation probabilities than younger ones (Figure $3 b$ ). Further important predictor variables were orientation $(16.3 \%)$ and city district (10.1\%). The Swifts slightly preferred northward facing boxes (Figure $3 \mathrm{c}$ ) and the boxes in Greifswald city centre had a markedly higher occupation probability than those in the two other districts (Figure $3 \mathrm{~d}$ ). The remaining box properties (relative absolute height, absolute height, manner of installation, and box type), had relative influences of $6.0,5.9,3.9$, and $2.9 \%$, respectively. Boxes at the roof edge and those placed higher than $11 \mathrm{~m}$ above ground had a higher occupation probability (Figure $3 \mathrm{e}, 3 \mathrm{f}$ ). The 116 occupied boxes had a mean absolute height $( \pm \mathrm{SD})$ of $13.49 \pm 2.95 \mathrm{~m}$. Furthermore, external boxes had a higher occupation probability than internal ones (Figure $3 \mathrm{~g}$ ). There were only negligible differences in occupation probability between the different box types (Figure $3 \mathrm{~h}$ ). However, within the Schwegler 17 group, single boxes (17 and 17/17B) were much more frequently occupied than triple boxes (17A; Table $3 \mathrm{e})$. 
Table 3. Number of surveyed nest-boxes and number and proportion of occupied boxes in the different categories of the box properties (raw data). NB = nest-box; prop. occ. NB = proportion of occupied nest-boxes. $\mathrm{s}=$ single box; $\mathrm{d}=$ double box; $\mathrm{t}=$ triple box.

\begin{tabular}{|c|c|c|c|}
\hline NB property / Category & \# NB & \# осc. NB & Prop. occ. NB (\%) \\
\hline \multicolumn{4}{|l|}{ a) Absolute height (m) } \\
\hline $5-7 \cdot 9$ & 15 & 2 & 13.3 \\
\hline 8-10.9 & 86 & 17 & 19.8 \\
\hline $11-13.9$ & 151 & 42 & 27.8 \\
\hline $14-19$ & 221 & 53 & 24.0 \\
\hline \multicolumn{4}{|l|}{ b) Box age (breeding periods) } \\
\hline $\mathrm{o}$ & 65 & 15 & 23.1 \\
\hline 1 & 49 & 15 & 30.6 \\
\hline 2 & 114 & 21 & 18.4 \\
\hline 3 & 75 & 3 & 4.0 \\
\hline 4 & 35 & 7 & 20.0 \\
\hline 5 & 35 & 18 & 51.4 \\
\hline 6 & 24 & 6 & 25.0 \\
\hline 7 & 36 & 10 & 27.8 \\
\hline 8 & 40 & 19 & $47 \cdot 5$ \\
\hline \multicolumn{4}{|l|}{ c) City district } \\
\hline City centre & 57 & 22 & 38.6 \\
\hline Ostseeviertel & 278 & 68 & $24 \cdot 5$ \\
\hline Schönwalde & 138 & 24 & $17 \cdot 4$ \\
\hline \multicolumn{4}{|l|}{ d) Manner of installation } \\
\hline Internal & 413 & 92 & 22.3 \\
\hline External & 60 & 22 & 36.7 \\
\hline \multicolumn{4}{|l|}{ e) NB type } \\
\hline Schwegler 17 group & 367 & 78 & 21.3 \\
\hline thereof Schwegler 17 (s) & 30 & 12 & 40.0 \\
\hline thereof Schwegler $17 / 17 B(\mathrm{~s})$ & 80 & 34 & 42.5 \\
\hline thereof Schwegler ${ }_{17} C(\mathrm{~d})$ & 2 & 1 & 50.0 \\
\hline thereof Schwegler $17 A(\mathrm{t})$ & 255 & 31 & 12.2 \\
\hline Schwegler $1 M F(\mathrm{~d})$ & 48 & 13 & 27.1 \\
\hline Strobel 416t (s) & 40 & 19 & $47 \cdot 5$ \\
\hline Strobel $416 \mathrm{~b}(\mathrm{~s})$ & 8 & 2 & 25.0 \\
\hline Strobel $430(\mathrm{~d})$ & 10 & 2 & 20.0 \\
\hline \multicolumn{4}{|l|}{ f) Number of neighbours } \\
\hline $\mathrm{O}$ & 69 & 29 & 42.0 \\
\hline 1 & 122 & 48 & $39 \cdot 3$ \\
\hline 2 & 183 & 30 & 16.4 \\
\hline $3-5$ & 39 & 7 & $17 \cdot 9$ \\
\hline $8-14$ & 60 & o & 0.0 \\
\hline \multicolumn{4}{|l|}{ g) Orientation } \\
\hline North & 120 & 29 & 24.2 \\
\hline East & 72 & 19 & 26.4 \\
\hline South & 153 & 35 & 22.9 \\
\hline West & 128 & 31 & 24.2 \\
\hline \multicolumn{4}{|l|}{ h) Relative height } \\
\hline At roof edge & 419 & $1 I I$ & 26.5 \\
\hline Not at roof edge & 54 & 3 & 5.6 \\
\hline Total & 473 & 114 & 24.1 \\
\hline
\end{tabular}




\section{Discussion}

\section{Nest-box occupancy}

The overall proportion of nest-boxes occupied by Swifts in Greifswald (24.3\%) was more than twice as high as that found in Berlin by Wortha and Arndt (2004). This discrepancy may be partly due to methodological differences between the studies. In the study by Wortha and Arndt, the observations were mostly conducted in the morning and early evening, while the Swift's feeding frequency peaks around noon in good weather, and again in the later evening (Lack and Owen 1955, Arens 2011). Additionally, the time when breeding Swifts return to their nests for the night (in the latitudes of northern Germany normally about 15-45 minutes after sunset; Church 1956, Arens 2011) was also not considered. In our study, older boxes showed higher occupation probabilities than recently installed ones. Hence, the overall occupancy rate of the examined boxes in Greifswald can be expected to grow even further in the near future.

The 116 occupied boxes in our study represented about a quarter of Greifswald's estimated Swift population (450-500 breeding pairs; Starke et al. 2010). The (minimum) population density of Swifts breeding in nest-boxes in the district Ostseeviertel Parkseite ( 34 breeding pairs per to ha) falls within the highest values of Swift densities given by Bauer et al. (2005). It is highly likely that fewer Swifts were breeding in this district before the onset of the extensive renovation works in 2004 (see Starke et al. 2010).

Our comparison of the number of breeding sites prior to renovation and in 2013 gave no indication of an overall decline. In contrast, Wortha and Arndt (2004) found the aggregate number of breeding pairs on 16 renovated buildings to be only about one third of the original number. On the other hand, results similar to ours were achieved in a project with nest-boxes as mitigation measures in England (D. Newell in litt. 2014). When interpreting our findings on breeding sites before renovation and in 2013, it should be noted that it was not possible to figure out details of the survey method (e.g. observation duration) used for the expert assessments prior to renovation. Possibly, less effort was expended in these assessments to determine the number of breeding sites than in our investigation. Thus, the number of breeding sites prior to renovation might have been underestimated. On the other hand, the nest-boxes on the 10 buildings regarded here had been installed only relatively recently (Table 1 ), and hence, the number of occupied boxes on these buildings will probably increase in the next years.

Our results confirm that nest-boxes for Swifts are frequently used by other cave-nesting bird species (e.g. Wortha and Arndt 2004), notably by House Sparrows that occupied nearly as many boxes than Swifts. Hence, installing surplus Swift boxes is probably an effective measure to support populations of the House Sparrow, another synanthropic species that showed declines during the last decades in Europe (PECBMS 2012) and that is red-listed in certain countries (Eaton et al. 2009).

\section{Influence of box properties on occupation probability}

The finding that boxes with no other boxes within $1 \mathrm{~m}$ had the highest occupation probability suggests that Swifts avoid to some degree breeding in the immediate vicinity of conspecifics. This is somewhat surprising, as it contradicts statements on the usual distances between Swift breeding - sites in buildings (Weitnauer and Scherner 1980). Colombo and Galeotti (1993) even reported that Swifts favoured breeding sites within $0.5 \mathrm{~m}$ of conspecifics. There are also anecdotal reports of large multi-compartment boxes where many cavities were simultaneously occupied (e.g. Kaiser 1993). In contrast, Thurston (1991) recommended installing nest-boxes with at least $0.5 \mathrm{~m}$ between the entrance holes. Possible disadvantages of nesting in close proximity to each other include an enhanced movement of parasites (such as the Common Swift Louse Fly Crataerina pallida; see Walker and Rotherham 2011) between nests, as well as an increased risk that Swifts enter the wrong nest site by mistake, which can lead to violent fights 
with the resident pair (Lack 1956). It is important to note that our results do not question that Swifts are gregarious breeders, but indicate that breeding pairs within a "colony" prefer distances of more than $1 \mathrm{~m}$ between nest sites if they have the opportunity to choose.

In our study, Swifts showed a preference for boxes situated higher than $11 \mathrm{~m}$. Other studies reported preferences for rather lower heights (Colombo and Galeotti 1993, Wortha and Arndt 2004). Corrales et al. (2013) found no preferences within 3.5-12.2 $\mathrm{m}$ height in a medieval city wall. However, in the latter study, higher cavities situated less than $1.7 \mathrm{~m}$ below the upper edge of the wall were avoided, probably because they were accessible to terrestrial predators. In contrast, we observed a higher occupation probability for nest-boxes located closer than $2 \mathrm{~m}$ to the roof edge. Theoretically, this could be explained by a shade-giving roof overhang, but most of the houses we investigated did not have such structures.

Although it is known that overheating of the nesting site can cause losses of Swift nestlings (Weitnauer 1980), we found only a slight preference for north-facing and no particular avoidance of south-facing boxes. It is worth noting, however, that we did not consider shadegiving structures (trees, other buildings, roof overhang) that may have reduced the risk of overheating in some cases. In other studies, no clear avoidance of south-facing breeding sites was found either (Colombo and Galeotti 1993, Wortha and Arndt 2004). In this context, it is also interesting that our analysis did not reveal a preference for internal boxes, which presumably protect better against overheating. In contrast, a survey in England found internal boxes to be largely preferred by Swifts (D. Newell in litt. 2014), whereas Wortha and Arndt (2004) reported no significant difference between internal and external boxes. In conclusion, the general recommendation not to mount boxes on south-facing aspects (Mayer 2013) cannot be supported. But, despite the lack of clear empirical evidence, it is probably advisable not to install nest-boxes (especially thin-walled models) externally on south-facing facades without shade-giving structures to avoid the risk of overheating.

We observed large differences in box - occupation probability across the three investigated districts of Greifswald. A reason for preferences for certain breeding areas could be shorter commuting distances to good feeding sites. However, this scenario probably does not apply to our case, as all three districts are not far from rural areas and from water bodies. A more plausible reason for the observed differences could be the very high supply of potential breeding sites in Ostseeviertel Parkseite ( 367 nest-boxes on 20 ha), where most boxes of the district Ostseeviertel were located. That may have led to a lower occupation probability per box. On the other hand, additional building renovations carried out during spring and summer 2013 in Greifswald city centre may have increased the demand of nesting sites in this district ( Du Feu 2003).

Between the different nest-box types, we observed only small differences in occupation probability. This suggests that all box types considered in our study are generally suitable for Swifts. This also applies to the boxes installed in the "wrong" way (Strobel 416t and 416b), which consequently had a smaller interior depth $(8.5$ and $4 \mathrm{~cm}$, respectively), and in the case of $416 \mathrm{t}$, a higher threshold at the entrance hole $(\mathrm{c} .8 \mathrm{~cm}$ ) than recommended (Kaiser 1993, Scholl 2004, Mayer 2013). The large difference in the rate of occupancy between the single and triple variants of the Schwegler 17 group can be explained by the avoidance of sites with many neighbouring boxes.

The moderate predictive performance of the model indicates that Swifts were relatively flexible with respect to the box properties studied. In addition, factors not considered in the present study may also have influenced the occupation probability. For example, the degree to which boxes were exposed to direct sunlight was only indirectly included in our analysis via facade orientation, and the total number of potential breeding sites in the surroundings was also not considered. The partially unbalanced study design (Table 3), which was unavoidable, may also have influenced some of our results. We did not measure breeding success, and some of the box properties (e.g. orientation) that apparently did not strongly affect the Swifts' choice of a box might still have influenced the reproductive outcome. Future investigations on that matter would thus be especially worthwhile. Finally, we want to reiterate that all buildings 
considered in the statistical analysis were renovated during the Swift breeding season. When renovation can be done outside the breeding season, the boxes should probably at best be installed exactly at the places of the original breeding sites to facilitate the boxes' discovery by the returning Swifts (Scholl 2004).

\section{Conclusions}

Our study provides several lines of evidence that nest-boxes for Common Swifts can be successful compensatory measures in the context of renovation and demolition works. First, the overall rate of box occupancy was relatively high. Secondly, the total number of occupied boxes was higher than the assumed number of breeding sites before the renovations. Thirdly, we recorded a remarkably high population density of Swifts breeding in nest-boxes in a district where nearly all buildings had been renovated in the past 10 years. If renovation has to be carried out during the Swift breeding season, our results suggest that nest-boxes should be installed a few metres apart from each other and close to the roof edge. Furthermore, it is probably somewhat preferable to mount the boxes externally, on north-facing facades and above II $\mathrm{m}$ height. In part, our findings do not conform to results of some other studies and anecdotal reports of Swift breeding-behaviour. Therefore, further investigations should be carried out to assess whether our results and conclusions can be confirmed in other situations.

\section{Supplementary Material}

The supplementary materials for this article can be found at journals.cambridge.org/bci

\section{Acknowledgements}

We are grateful to the numerous observers who took part in the nest-box survey; to the Abteilung Umwelt- und Naturschutz, Stadtbauamt, Universitäts- und Hansestadt Greifswald for financial support; to the Landesamt für Umwelt, Naturschutz und Geologie MecklenburgVorpommern (LUNG) and to J. Berg for providing the expert assessments; to the housing corporations WVG and WGG Greifswald for additional information on the examined buildings; and to C. Schöner, J. van Schaik, P. Atkinson and D. Newell for helpful comments on the manuscript.

\section{References}

Åkesson, S., Klaassen, R., Holmgren, J., Fox, J.W. and Hedenström, A. (2012) Migration routes and strategies in a highly aerial migrant, the Common Swift Apus apus, revealed by lightlevel geolocators. PLoS ONE 7: e41195.

Arens, H. (2004) Gelungene Ansiedlung von Mauerseglern an einem Einfamilienhaus. Der Falke 51: 51. (In German).

Arens, H. (2011) Breeding biology of a pair of Swifts Apus apus ringed with an attached transponder. Vogelwelt 132: 153-160. (In German with English summary).

Bauer, H.-G., Bezzel, E. and Fiedler, W., eds. (2005) Das Kompendium der Vögel Mitteleuropas. Vol. 1: Nonpasseriformes. 2nd edition. Wiesbaden, Germany: Aula. (In German).

BirdLife International (2004) Birds in Europe: population estimates, trends and conservation status. Cambridge, UK: BirdLife International.

BMWi, ed. (2011) Second National Energy Efficiency Action Plan (NEEAP) of the Federal Republic of Germany. Pursuant to the EU Directive on energy end-use efficiency and energy services (2006/32/EC). Berlin, Germany: Federal Ministry of Economics and Technology.

Braun, H.-G. (1999) Effects of restoration of old buildings on an urban breeding avifauna: ornitho-ecological studies in Berlin-Kreuzberg. Vogelwelt 120: 39-51. (In German with English summary).

Church, H. F. (1956) The roosting times of the Swift. Bird Study 3: 217-220. 
Colombo, A. and Galeotti, P. (1993) Nest-hole selection as defence measure in breeding Swifts (Apus apus). Avocetta 17: 1-6.

Corrales, L., Bautista, L. M., Santamaría, T. and Mas, P. (2013) Hole selection by nesting swifts in medieval city-walls of central Spain. Ardeola 60: 291-304.

Cramp, S., ed. (1985) Handbook of the birds of Europe, the Middle East and North Africa. Vol. 4: Terns to woodpeckers. Oxford, UK: Oxford University Press.

Crowe, O., Coombes, R. H., Lysaght, L., O'Brian, C., Choudhury, K. R., Walsh, A. J., Wilson, J. H. and O'Halloran, J. (2010) Population trends of widespread breeding birds in the Republic of Ireland 1998-2008. Bird Study 57: 267-280.

Czech, B., Krausman, P. R. and Devers, P. K. (2000) Economic associations among causes of species endangerment in the United States. BioScience 50: 593-601.

Deutscher Bundestag (2009) Gesetz über Naturschutz und Landschaftspflege (Bundesnaturschutzgesetz - BNatSchG). 29 July 2009. Bundesgesetzblatt I: $2542-$ 2573. (In German).

Du Feu, C. (2003) The BTO nestbox guide. Thetford, UK: British Trust for Ornithology.

Eaton, M. A., Brown, A. F., Noble, D. G., Musgrove, A. J., Hearn, R. D., Aebischer, N. J., Gibbons, D. W., Evans, A. and Gregory, R. D. (2009) Birds of conservation concern 3. The population status of birds in the United Kingdom, Channel Islands and Isle of Man. Br. Birds 102: 296-341.

Elith, J., Leathwick, J. R. and Hastie, T. (2008) A working guide to boosted regression trees. J. Anim. Ecol. 77: 802-813.

EU (2012) Directive 2012/27/EU of the European Parliament and of the Council of 25 October 2012 on energy efficiency, amending Directives 2009/125/EC and 2010/ 30/EU and repealing Directives 2004/8/ EC and 2006/32/EC. Off. J. Eur. Union L 315: 1-56.

Friedman, J. H. (2001) Greedy function approximation: a gradient boosting machine. Ann. Stat. 29: 1189-1232.

Friedman, J. H. and Meulman, J. J. (2003) Multiple additive regression trees with application in epidemiology. Stat. Med. 22: $1365-1381$.
Gory, G. (1997) Apus apus - Swift. Pp. 426-427 in E. J. M. Hagemeijer and M. J. Blair, eds. The EBCC atlas of European breeding birds: their distribution and abundance. London, UK: Poyser.

Günther, E., Hellmann, M. and Nicolai, B. (2004) Tree-breeding Common Swifts Apus apus - relicts of ancient forest features? Vogelwelt 125: 309-318. (In German with English summary).

Kaiser, E. (1993) Schutzmöglichkeiten für Mauersegler. Vogel und Umwelt 7: 307-312. (In German).

Lack, D. (1956) Swifts in a tower. London, UK: Chapman and Hall.

Lack, D. and Lack, E. (1951) The breeding biology of the Swift Apus apus. Ibis 93: 501-546.

Lack, D. and Owen, D. F. (1955) The food of the Swift. J. Anim. Ecol. 24: 120-136.

Laurance, W. F. (2010) Habitat destruction: death by a thousand cuts. Pp. $73-87$ in N. S. Sodhi and P. Ehrlich, eds. Conservation biology for all. Oxford, UK: Oxford University Press.

Lehmann, B. (2005) Berücksichtigung des Artenschutzes beim Rückbau von Plattenbauten. Naturschutz im Land Sachsen-Anhalt 42: 41-47. (In German).

Luniak, M. and Grzeniewski, M. (2011) Nest-boxes for the Common Swift Apus apus - experience from Poland. Ecologia Urbana 23: 3-5.

Mayer, E. (2013) Creating Swift nest places in old $\mathcal{E}$ new soffits. Swift Conservation. http://www.swift-conservation.org/ Creating \% 20 Swift \% 20Nest \% 2oPlaces $\%$ 2 oin $\%$ 2oOld $\%$ zoand $\%$ 2o New $\% 20$ Soffits \% 20\% 28small\% 29.pdf (accessed on 24 November 2014).

Mcdonald, R. I., Kareiva, P. and Forman, R. T. (2008) The implications of current and future urbanization for global protected areas and biodiversity conservation. Biol. Conserv. 141: 1695-1703.

PECBMS (2012) Population trends of common European breeding birds 2012. Prague, Czech Republic: Czech Society for Ornithology.

$\mathrm{R}$ Core Team (2013) R: a language and environment for statistical computing. Vienna, Austria: R Foundation for Statistical Computing. 
Ridgeway, G. (2013) Gbm: generalized boosted regression models. $R$ package version 2.1 .

Scholl, I. (2004) Nistplätze für Mauer- und Alpensegler. Praktische Informationen rund um Baufragen. Zürich \& Sempach, Switzerland: Schweizer Vogelschutz \& Schweizerische Vogelwarte. (In German).

Starke, W., Bendt, R., Köhler, J., Luhn, M. and Sellin, D. (2010) Die Brutvögel der Stadt Greifswald. Ergebnisse einer halbquantitativen Gitterfeldkartierung der Brutvögel in den Jahren 1999-2004 einschl. Ergänzungen bis 2008. Greifswald, Germany:Institut für Landschaftsökologie und Naturschutz. (In German).

Statistisches Amt Mecklenburg-Vorpommern (2013) Bevölkerungsstand der Kreise, Ämter und Gemeinden in MecklenburgVorpommern. 30 June 2013. http://service. mvnet.de/statmv/daten_stam_berichte/ebibointerthor/bevoelkerung-haushaltefamilien-flaeche/a-i_/a123_/2013/ daten/a123-2013-21.pdf (accessed on 24 November 2014). (In German).

Südbeck, P., Bauer, H.-G., Boschert, M., Boye, P. and Knief, W. (2007) The Red List of breeding birds of Germany, 4th edition, 30 November 2007. Berichte zum Vogelschutz 44: 23-81. (In German with English summary).

Sudfeldt, C., Bairlein, F., Dröschmeister, R., König, C., Langgemach, T. and Wahl, J. (2012) Vögel in Deutschland - 2012. Münster, Germany: Dachverband Deutscher Avifaunisten, Bundesamt für Naturschutz \& Länderarbeitsgemeinschaft der Vogelschutzwarten. (In German).
Thurston, P. (1991) Bauen für Segler. Leitfaden für Architekten, Handwerker, Hauseigentümer, Bauherren und Naturund Vogelschützer. 2nd edition. Zürich, Switzerland: Gartenbauamt der Stadt Zürich \& Zürcher Vogelschutz. (In German).

Tigges, U. and Mayer, E. (2011) How to use the Swift calls CD. Swift Conservation. http:// www.swift-conservation.org/How_to_use_ the_Swift_Calls_CDv4.pdf (accessed on 24 November 2014).

Walker, M. D. and Rotherham, I. D. (201I) Discovery of internest dispersal by Crataerina pallida (Diptera:Hippoboscidae). Ann. Entomol. Soc. Am. 104: 847-849.

Weitnauer, E. (1980) "Mein Vogel". Aus dem Leben des Mauerseglers Apus apus. Liestal, Switzerland: Basellandschaftlicher Natur- und Vogelschutzverband. (In German).

Weitnauer, E. and Scherner, E. R. (1980) Apus apus - Mauersegler. Pp. 671-712 in U. N. Glutz von Blotzheim and K. M. Bauer, eds. Handbuch der Vögel Mitteleuropas. Vol. 9: Columbiformes - Piciformes. Wiesbaden, Germany:Akademische Verlagsgesellschaft. (In German).

Wilson, J. S. (2011) Nest site conservation action for the Common Swift Apus apus in Scotland 2000-2010. Ecologia Urbana 23: 6-12.

Wortha, S. and Arndt, E. (2004) Acceptance of nest-boxes by the Common Swift (Apus apus) in Berlin. Berichte zum Vogelschutz 41: 113-126. (In German with English summary).

\section{TONIO SCHAUB*, GERALD KERTH}

Zoological Institute and Museum, Ernst Moritz Arndt University of Greifswald, Greifswald, Germany.

\section{PETER J. MEFFERT}

Institute for Community Medicine, Ernst Moritz Arndt University of Greifswald, Greifswald, Germany.

${ }^{*}$ Author for correspondence; e-mail: tonio.schaub@posteo.de 